\title{
Verificação do Estado-limite de Serviço em Vigas de Concreto Armado Visando a Durabilidade em Projeto Estrutural
}

\author{
Verification of the Serviceability Limit State in Reinforced Concrete Beams Aiming at \\ Durability in Structural Design
}

\section{Amâncio da Cruz Filgueira Filho ${ }^{1}$ (D) orcid.org/0000-0001-5231-3656}

Rafael Filgueira Amaral ${ }^{1}$ (D) orcid.org/0000-0001-7115-8874

Bruno de Sousa Teti ${ }^{2}$ (D) orcid.org/0000-0003-4881-5287

Iago Santos Calábria ${ }^{3}$ id orcid.org/0000-0001-8194-0085

\footnotetext{
${ }^{1}$ Departamento de Engenharia Civil, Universidade Católica de Pernambuco, Recife, Brasil.

2 Departamento de Pós-Graduação em Segurança do Trabalho, Universidade de Pernambuco, Recife, Brasil,

3 Departamento de Pós-Graduação em Engenharia de Saneamento Básico e Ambiental, Instituto Brasileiro de Educação Continuada, Recife, Brasil.

E-mail do autor principal: Amâncio da Cruz Filgueira Filho amanciofilgueira@hotmail.com
}

Resumo

Nos últimos anos o conceito de durabilidade de estruturas vem ganhando uma maior importância, principalmente com atualizações de normas técnicas. A vida útil de estruturas de concreto armado depende do cumprimento de uma série de fatores, que devem ser definidos em projeto, e atendidos na execução e em manutenções. Do ponto de vista econômico as medidas de correção tomadas logo na fase de projeto são menos onerosas, é nesta fase que se deve ter um cuidado minucioso das decisões para não acarretar custos maiores nas demais etapas da vida útil da estrutura. É de extrema importância para um adequado projeto de estruturas levar em conta as verificações do estado-limite de serviço (ELS), pois estes critérios acarretarão benefícios ao produto final, aumentando a vida útil da estrutura e evitando desconfortos à aceitabilidade sensorial do usuário, como possíveis gastos futuros de manutenção corretiva. Este trabalho tem como objetivo se fazer verificações do estadolimite de serviço para um projeto de uma edificação, com o objetivo de evitar futuras manifestações patológicas principalmente ligadas à degradação do concreto e ao fenômeno de corrosão de armaduras. Foram levados em conta para verificação em serviço os deslocamentos-limite e a abertura máxima de fissuras em vigas do pavimento tipo da edificação em estudo. Os resultados presentes neste trabalho foram obtidos com o software CAD/TQS, e foi feito um processamento não-linear para considerar o efeito incremental das cargas, levando em conta os efeitos construtivos, fluência e fissuração. Sendo assim uma análise mais próxima do comportamento real da estrutura.

Palavras-Chave: Durabilidade; estado-limite de serviço; projeto; fissuras; deslocamentos. 


\begin{abstract}
In the last years the concept of durability of structures has been gaining more importance, mainly with updates of technical norms. The service life of reinforced concrete structures depends on the fulfillment of a series of factors that must be defined in design, and fulfilled in the execution and in maintenance. From the economic point of view, the corrective measures taken at the design stage are less costly, it is at this stage that careful attention must be paid to the decisions in order not to entail higher costs of the other stages of the service life of the structure. It is of extreme importance for an adequate design of structures to take into account the checks of the serviceability limit state (SLS), as these criteria will bring benefits to the final product, increasing the useful life of the structure and avoiding discomfort to the user's sensory acceptability, such as possible future expenses of corrective maintenance. The objective of this work is to verify the serviceability limit state for a project of a building, with the objective of avoiding future pathological manifestations mainly related to concrete degradation and to the corrosion phenomenon of reinforcement. The limit displacements and the maximum crack opening in beams of the type pavement of the building under study were taken into account for service verification. The results presented in this work were obtained with CAD/TQS software, and a nonlinear processing was done to consider the incremental effect of the loads, taking into account the constructive effects, creep and cracking. This is a closer analysis of the actual behavior of the structure.
\end{abstract}

Key-words: Durability; serviceability limit state; design; cracks; displacements.

\section{Introdução}

O material de maior importância e utilização na construção civil mundial é o concreto. Diversas são as vantagens deste material, no qual se pode destacar a facilidade de obtenção de seus componentes, a trabalhabilidade, o seu bom comportamento perante solicitações normais, e a suas técnicas construtivas são facilmente dominadas.

O concreto é normalmente feito com a mistura de cimento Portland com areia, pedra (brita) e água. Em diversos países estima-se que o consumo de concreto é 10 vezes maior que o de aço. Segundo Brunauer e Copeland (1964) apud Mehta e Monteiro (2014), comentam em que relação ao concreto o homem não consome nenhum outro material em tal quantidade, a não ser água [11].

Para utilização estrutural, o concreto sozinho apresenta deficiência quando se refere as demais solicitações, estima-se que a sua resistência de tração é cerca de $10 \%$ da resistência à compressão. Os esforços de tração estão presente na maior parte das peças estruturais, como no caso de peças fletidas que numa mesma seção transversal está submetida à esforços de tração e compressão.

Um exemplo seria o caso de uma viga de simplesmente apoiada de concreto, submetida à flexão pura, à qual dependendo da intensidade dos esforços podem gerar fissuras na face inferior da viga nas proximidades do centro do vão. Pois nessa região esforços de flexão estão conferindo valores maiores, e devida a baixa resistência à esforços de tração, às deformações causadas irão gerar estas pequenas trincas, como na Figura 1

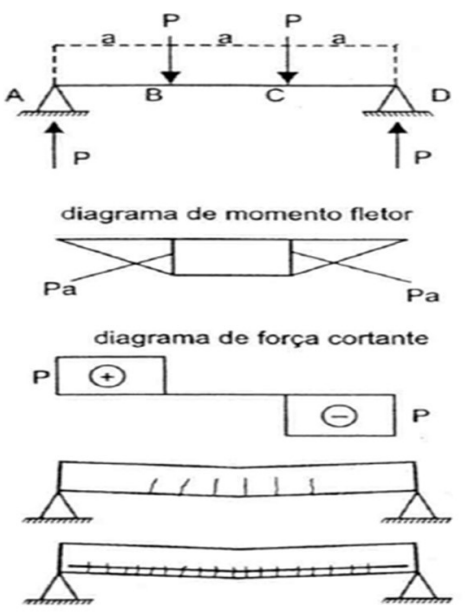

Figura 1: Comportamento de uma viga simplesmente apoiada de concreto. Fonte: Carvalho (2014)

Daí para o concreto poder trabalhar de uma maneira satisfatória perante aos esforços presentes nas mais diversas estruturas, é necessário reforçar 
este com barras de aço, material que possui boa resistência a tração e é mais deformável. A esse trabalho solidário entre os materiais concreto e aço confere ao concreto consistido de armaduras, chamado de concreto armado. A interação de ambos os materiais tornam esse conjunto um sistema de excelente função estrutural, no qual a armadura metálica deve suprir as deficiências do concreto simples.

A fissuração está presente em estruturas de concreto armado, logo estas são passivas a manifestações patológicas devido a este problema. Assim é necessário evitar-se ao máximo aberturas maiores que as estabelecidas por norma, daí então deve ser dado uma grande importância das verificações de estado-limite de serviço, objetivando reduzir estas aberturas como também evitar deslocamentos excessivos. O objetivo deste trabalho é mostrar a importância destas verificações, buscando-se à durabilidade da estrutura, fazendo-se um controle de níveis de fissuração e deslocamentos à caráter de projeto.

\section{Durabilidade em projeto de estruturas de concreto armado}

\subsection{Estados-limite}

Para se determinar os esforços presentes numa estrutura, os materiais a serem utilizados, e demais considerações de projeto, devem ser feita previamente uma Análise estrutural. Esta que é a determinação dos efeitos que cargas geram nas estruturas físicas e seus componentes. São submetidas a este tipo de análise todas as estruturas que devem resistir a cargas, tais como edifícios, pontes, veículos, máquinas, camadas do solo, entre outros.

Numa estrutura de concreto, sua segurança deve ser sempre verificada em relação aos estados-limites. Os estados limites são situações as quais a estrutura deixa atender requisitos necessários para seu uso de forma plena e adequada, (KIMURA, 2010) [9]. Carvalho (2014) os diferencia citando que o estadolimite ultimo é aquele relacionado ao colapso ou a qualquer outra forma de ruína estrutural que determine a paralisação, no todo ou em parte, do uso da estrutura, enquanto que o estado-limite de serviço é aquele relacionado à durabilidade das estruturas, à aparência, ao conforto do usuário e à boa utilização funcional das mesmas, seja em relação aos usuários como às maquinas e equipamentos utilizados [6].

Ainda do estado-limite de serviço, existem ainda subdivisões deste a qual se podem ser lavados em conta com o propósito de aumentar a vida útil das estruturas de concreto armado segundo a ABNT NBR 6118:2014. Estes são:

Estado-limite de formação de fissuras (ELS-F), estado em que se inicia a formação de fissuras. Admite-se que este estado-limite é atingido quando a tensão de tração máxima na seção transversal for igual a resistência à tração na flexão $\left(f_{c t, f}\right)$.

Estado-limite de abertura das fissuras (ELS-W), estado em que as fissuras se apresentam com aberturas $\left(w_{\mathrm{k}}\right)$ iguais aos máximos especificados de acordo com o tipo de concreto estrutural e a classe de agressividade ambiental.

Estado-limite deformações excessivas (ELS-DEF), estado em que as deformações atingem os limites estabelecidos para a utilização normal. [1]

\subsection{Vida útil}

Estas verificações de estados limite de serviço são de extrema importância tanto para a vida útil funcional ou estrutural, ambas que irão evitar ao usuário final desconfortos perante patologias e manutenções corretivas. A vida útil funcional é aquela ligada a rentabilidade do investimento da estrutura, garantindo sua mais completa utilização por seu usuário final, já a vida útil estrutural deve garantir que a estrutura seja resistente perante as solicitações a qual foi projetada durante este período definido.

Segundo Andrade, Costa e Silva (2009) tanto os construtores como clientes da construção civil, querem que as estruturas tenham vida longa, para que se possam evitar futuros gastos com manutenções e reparos, ainda que o material concreto possua boa durabilidade, este perderá suas características ao longo do tempo [3].

$\mathrm{Na}$ ACI 201.2R (ACI, 2001) conceitua que um concreto durável, é aquele que possui capacidade de resistir ao intemperismo, ataque químico, desgaste por abrasão ou qualquer outro processo de deterioração, retendo a sua forma original, qualidade

http://dx.doi.org/10.25286/repa.v2i3.687 
e capacidade de utilização, quando exposto ao ambiente de trabalho [2].

Andrade, Costa e Silva (2009) ainda observam que o fator "tempo" não foi citado, e que intuitivamente, na definição de durabilidade, não se pode excluir essa variável, pois os mecanismos de deterioração atuam de forma gradativa, ao longo de vida da estrutura e que quando não é introduzido esse fator, esta propriedade passa a ser meramente subjetiva, não podendo ser quantificada [3].

Do ponto de vista econômico as medidas de correção tomadas logo na fase de projeto são mais baratas, é nesta fase que devem ser ter um cuidado mais minucioso das decisões a serem tomadas e suas possíveis correções, para não acarretar um custo mais elevado nas próximas etapas de vida da estrutura.

Quanto mais tarde for essa intervenção a evolução desse custo pode ser compreendido como uma progressão geométrica de razão 5 , conforme Figura 2, conhecido como a lei dos 5 ou a regra de Sitter (HELENE 1997) [8].

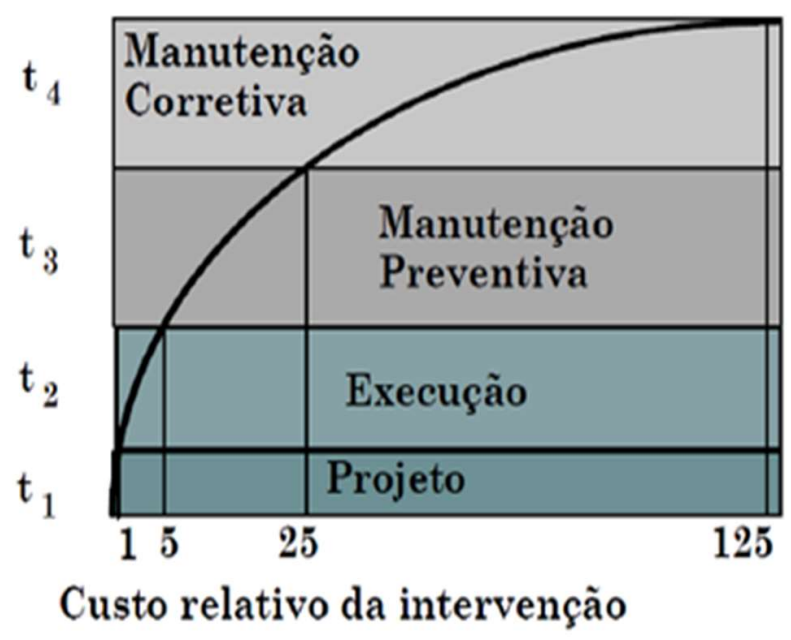

Figura 2: Evolução dos custos em função da fase da vida útil da estrutura em que a intervenção é feita. Fonte: Helene (1997).

\section{Fissuras}

\subsection{Fissuras em elementos de concreto armado}

As fissuras são aberturas que se instalam na superfície da estrutura e facilitam a entrada de agentes nocivos. Para Thomaz (1989), os elementos e componentes construtivos se sujeitam a variações térmicas relacionadas às suas propriedades físicas diariamente, o que varia as suas dimensões por meio da dilatação e contração. A amplitude e a velocidade de tais movimentações térmicas devem ser consideradas para a análise das fissuras. Elas também podem surgir em consequência de alternância de ciclos de carregamento e descarregamento ou por solicitações alternadas de tração e compressão, bem como pela retração do concreto em função da rápida evaporação da água em seu processo de cura [12].

A estrutura em concreto armado se comporta trabalhando de maneira conjunta dos materiais concreto e aço, agindo em resposta a solicitações a que eles foi dada. Segundo Marins Neto (2007), a fissuração nos elementos de concreto endurecido é praticamente inevitável, pois, antes da aplicação de qualquer tipo de carregamento, o concreto já pode apresentar microfissuras decorrentes da variação de volume e da hidratação do cimento [10].

Com a transmissão do carregamento numa estrutura, as microfissuras vão aumentando, que podem tornar-se fissuras conferindo uma perda de seção resistente do material, e promovendo a entrada de agentes causadores de patologias. O concreto armado, deixa sua fase linear logo no começo do aparecimento das fissuras, resultando numa não proporcionalidade de suas tensões com as deformações, conferindo a este ser um material nãolinear.

Chan (1994) e Wang (2001) afirmam que os efeitos da fissuração na rigidez lateral de edifícios altos de concreto armado devem ser avaliados com precisão, já que o projeto de tais estruturas deve atender aos valores limites de deslocamentos, no topo e entre pavimentos [7] [13].

A consideração da não-linearidade física dos materiais é essencial para que seja estabelecida corretamente a capacidade resistente das estruturas de concreto armado, (BUCHAIM, 2001) [5], isso se torna preponderante, pois vários fatores conferem esse comportamento como a fissuração, fluência, processos construtivos, cargas aplicadas corretamente em serviço e os efeitos do tempo, (ARAUJO, 2002) [4]. 


\subsection{Degradação decorrentes da fissuração}

O principal fenômeno de degradação em estruturas de concreto armado decorrente da fissuração é a sua evolução atingindo a armadura. Esta que passará pelo processo de corrosão e comprometerá a estabilidade da estrutura em si.

Pode-se definir corrosão como a interação destrutiva de um material com o ambiente, seja por reação química, ou eletroquímica. A oxidação e a corrosão propriamente dita podem ser consideradas como um dos principais processos de degradação que as armaduras de aço para concreto armado podem sofrer.

Os principais mecanismos de degradação estão associados a uma estrutura fissurada é a corrosão de armaduras devido à carbonatação do concreto e/ou ataque causado por íons cloretos.

A evolução da corrosão das armaduras nas regiões das fissuras na direção transversal causada por esforços de flexão, depende da qualidade do concreto e espessura do cobrimento. A abertura máxima característica de fissuras $\left(w_{\mathrm{k}}\right)$ em estruturas de concreto armado, sob ação de combinações frequentes no ELS-W, não deve exceder os limites estabelecidos na NBR 6118:2014 [1], apresentados a seguir na Tabela 1.

Tabela 1: Abertura máxima de fissuras de estrutura de concreto armado em função da classe de agressividade ambiental.

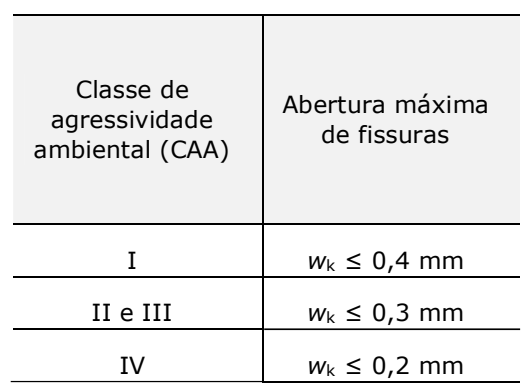

Fonte: ABNT NBR 6118 (2014), (adaptada).

Outra maneira de garantir uma boa funcionalidade da estrutura é se verificando os deslocamentos-limites, utilizados para se verificar as deformações excessivas da estrutura no ELS-DEF [1], na Tabela 2 serão expostas as verificações usuais em serviço para projeto de edifícios de estruturas de concreto armado.

Tabela 2: Limites para deslocamentos de edificações.

\begin{tabular}{|c|c|c|c|}
\hline Tipo de efeito & $\begin{array}{l}\text { Razão da } \\
\text { limitação }\end{array}$ & $\begin{array}{l}\text { Deslocamento } \\
\text { a considerar }\end{array}$ & $\begin{array}{l}\text { Deslocamento- } \\
\text { limite }\end{array}$ \\
\hline $\begin{array}{l}\text { Aceitabilidade } \\
\text { sensorial }\end{array}$ & $\begin{array}{c}\text { Deslocamentos } \\
\text { visíveis em } \\
\text { elementos } \\
\text { estruturais }\end{array}$ & Total & $L / 250$ \\
\hline \multirow{2}{*}{$\begin{array}{l}\text { Efeitos em } \\
\text { elementos } \\
\text { não } \\
\text { estruturais }\end{array}$} & Paredes & $\begin{array}{c}\text { Após a } \\
\text { construção da } \\
\text { parede }\end{array}$ & $\begin{array}{c}L / 500 \text { e } 10 \\
\mathrm{~mm} \mathrm{e} \\
\theta=0,0017 \\
\text { rad }\end{array}$ \\
\hline & $\begin{array}{l}\text { Movimento } \\
\text { lateral de } \\
\text { edifícios }\end{array}$ & $\begin{array}{l}\text { Ação do vento } \\
\text { para } \\
\text { combinação } \\
\text { frequente } \psi 1 \\
=0,30\end{array}$ & $\begin{array}{l}H / 1700 \text { e } H_{\mathrm{i}} \\
\text { entre } \\
\text { pavimentos }\end{array}$ \\
\hline
\end{tabular}

Fonte: ABNT NBR 6118 (2014), (adaptada).

\section{Metodologia}

Neste trabalho serão feitas verificações em serviço em vigas de concreto armado de um edifício usual, para se verificar se este está atendendo as prescrições da NBR 6118:2014 para verificações de deformações excessivas e abertura máxima de fissuras.

O objetivo desta análise é saber se o edifício está atendendo a estado limite de serviço para estrutura de concreto armado, para evitar-se futuras patologias decorrentes da fissuração antes de sua execução.

Como visto no capítulo 2 deste trabalho, as intervenções sempre que possível devem ser realizadas na fase de projeto, pois são bem menos onerosas, e intervenções em cada fase posterior de sua vida acontecem como uma progressão geométrica de razão cinco (HELENE, 1997) [8].

Com o objetivo de se obter um comportamento mais próximo da realidade o edifício será analisado considerando a não-linearidade física, consequentemente os efeitos de fissuração, fluência e a perca gradativa da rigidez.

O software utilizado para análise deste trabalho foi o CAD/TQS, o qual está totalmente adaptado à atual NBR 6118, e sua metodologia e representação está 
usualmente empregada conforme a da maioria dos escritórios de cálculo estrutural.

\section{Estudo de Caso}

\subsection{Descrição do Edifício}

O projeto consiste em um edifício em concreto armado de 4 pavimentos, sendo 3 pavimentos tipo e uma cobertura, totalizando $11,2 \mathrm{~m}$ de altura, com pé direito de $2,8 \mathrm{~m}$ para todos os pavimentos.

O pavimento consiste em um modelo muito usual em edifícios residenciais, consistindo em quatro apartamentos por andar, dois elevadores e escada. Sua estrutura é composta por 12 lajes (considerando uma da escada), 24 vigas e 22 pilares, conforme projeto estrutural demonstrado na Figura 3, e melhor apresentado no Apêndice I.

Dimensões:

Pilares: 24x65, 110x24, 24x290, 20x90, $20 \times 40,20 \times 140$ e $20 \times 160$ (dimensões em cm)

Vigas: $24 \times 55,14 \times 55$ e 16×55 (dimensões em cm)

Lajes: espessura $=12 \mathrm{~cm}$.

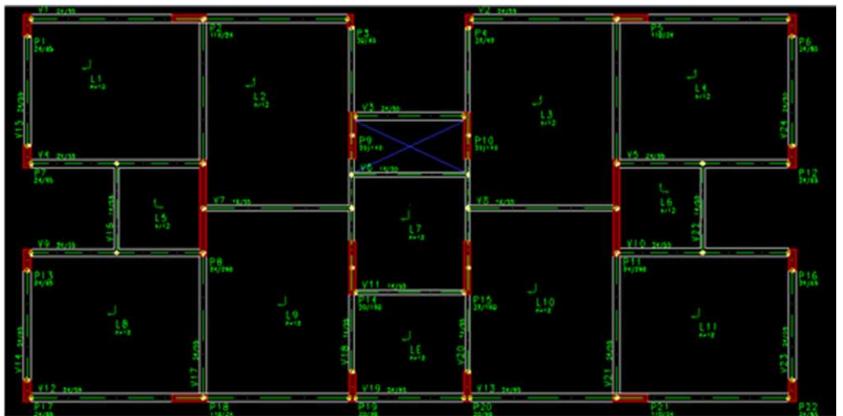

Figura 3: Projeto estrutural do edifício.

Fonte: Autoria própria (2017).

O material utilizado para a estrutura do o edifício foi o concreto armado com resistência característica à compressão: $f_{c k}=25 \mathrm{MPa}$ e aço CA-50 $\left(f_{\mathrm{yk}}=500\right.$ $\mathrm{MPa})$.

A classe de agressividade ambiental, definida com base na tabela 6.1 da NBR 6118:2014, foi a classe II - Moderada - Urbana, com risco de deterioração da estrutura pequeno.

Os cobrimentos a serem empregados na estrutura obedecem aos valores da tabela 7.2 da NBR
6118:2014, na qual tem relação com a classe de agressividade ambiental. Para lajes foi de $2,5 \mathrm{~cm}$, vigas e pilares de $3,0 \mathrm{~cm}$, e para fundações de $3,0 \mathrm{~cm}$.

\subsection{Cargas}

Para as lajes o valor da carga devido ao peso próprio ( $\mathrm{gL}$ ) é calculada pela multiplicação de três fatores: o peso específico do concreto $\left(\gamma_{c}\right)$ de 2,5 $\mathrm{tf} / \mathrm{m}^{3}$ (para C25), a espessura da laje (e) e a sua respectiva área $(A L)$, conforme a Equação (1).

$$
\mathrm{gL}=\gamma_{c} \cdot e \cdot \mathrm{AL} .
$$

Nas vigas o valor da carga do peso próprio ( $\mathrm{gV}$ ) é obtida pela multiplicação entre do peso específico do concreto em uso $\left(2,5 \mathrm{tf} / \mathrm{m}^{3}\right)$, as dimensões da viga (b.h) e o seu vão (I), conforme a Equação (2).

$$
\mathrm{gV}=\gamma \mathrm{c} \cdot \mathrm{b} \cdot \mathrm{h} \cdot \mathrm{I}
$$

Nas lajes foram também consideradas cargas distribuídas, provenientes de carga permanente de $0,1 \mathrm{tf} / \mathrm{m}^{2}$ e carga variável de $0,15 \mathrm{tf} / \mathrm{m}^{2}$.

Nas vigas, ainda foram solicitadas cargas distribuídas provenientes das alvenarias de vedação de bloco 14 de concreto que estão sobre as vigas, no valor de 0,26 tf/m² com altura de 2,25 m.

Ainda no pavimento tipo existem cargas linearmente distribuídas sobre algumas lajes, devido as alvenarias de vedação nas paredes internas da edificação, também definidas com valor de carga permanente de $0,26 \mathrm{tf} / \mathrm{m}^{2}$ para alvenarias de bloco 14 de concreto, estas levantadas a uma altura de 2,7 m.

\subsection{Análise não-linear física}

Na análise não-linear, o carregamento total definido no pavimento é subdividido em incrementos de cargas, de tal forma que a rigidez em cada ponto da estrutura possa ser corrigida gradativamente à medida que a fissuração se propaga.

Quanto maior o número de incrementos, mais precisos serão os resultados obtidos, porém o processamento será mais lento. O número de incrementos definidos foi de 12 (doze).

Daí foi definido a quantidade para cada parcela de carga de acordo com a sua relevância na carga total.

De forma aproximada foi definido os valores das parcelas do incremento de carga utilizados as 
reações obtidas na grelha conforme mostra a Tabela 3.

Tabela 3: Parcelas de carga para a análise incremental.

\begin{tabular}{c|l|c|c|c}
\hline Caso & Tipo de carga & Reação & Porcentagem & $\begin{array}{c}\text { Parcelas } \\
\text { de carga }\end{array}$ \\
\hline 1 & Vertical total & $\begin{array}{c}299,67 \\
\mathrm{tf}\end{array}$ & $100 \%$ & 12 \\
\hline 2 & Peso próprio & $\begin{array}{c}111,72 \\
\mathrm{tf}\end{array}$ & $37,3 \%$ & 4 \\
\hline 3 & Permanentes & $\begin{array}{c}150,42 \\
\mathrm{tf}\end{array}$ & $50,2 \%$ & 6 \\
\hline 4 & Variáveis & $\begin{array}{c}37,53 \\
\mathrm{tf}\end{array}$ & $12,5 \%$ & 2 \\
\hline
\end{tabular}

Fonte: Autoria própria (2017).

\subsection{Verificação dos deslocamentos- limites}

Foram verificados os deslocamentos-limite em todos os vãos de cada viga do pavimento tipo, estes devem obedecer aos valores-limites de deslocamentos que visando proporcionar um adequado comportamento da estrutura em serviço, obedecendo a valores da tabelados em norma, conforme Tabela 4, o movimento lateral do edifício não foi calculado devido a ser um edifício de poucos pavimentos e a carga do vento não ser preponderante nos resultados.

Os valores-limites a serem analisados no trabalho são:

- Deslocamentos visíveis em elementos estruturais (vigas e lajes): //250.

- Alvenaria, caixilhos e revestimentos após construção de paredes: I/500 ou;

- Deslocamento limite sob alvenaria após sua construção: $10 \mathrm{~mm}$.

- Rotação limite sob alvenaria após sua construção: $\theta=0,0017$ rad.

Tabela 4: Comparativo dos valores obtidos dos deslocamentos de flechas nas vigas com os valores limite estabelecidos na NBR 6118:2014.

\begin{tabular}{c|c|c|c|c|c|c|c}
\hline Viga & Vão & $L(\mathrm{~cm})$ & $\begin{array}{c}f \\
(\mathrm{~cm})\end{array}$ & $\theta(\mathrm{rad})$ & $\begin{array}{c}f \lim . \\
(\mathrm{cm})\end{array}$ & $\begin{array}{c}\theta \lim . \\
(\mathrm{rad})\end{array}$ & Situação \\
\hline V1 & 1 & 500,75 & 0,08 & 0,0002 & 1,00 & 0,0017 & Passou \\
\hline
\end{tabular}

\begin{tabular}{c|c|c|c|c|c|c|c} 
& 2 & 501,75 & 0,08 & 0,0003 & 1,00 & 0,0017 & Passou \\
\hline \multirow{2}{*}{ V2 } & 1 & 501,75 & 0,08 & 0,0003 & 1,00 & 0,0017 & Passou \\
\cline { 2 - 8 } & 2 & 501,25 & 0,08 & 0,0002 & 1,00 & 0,0017 & Passou \\
\hline V3 & 1 & 351,50 & 0,05 & 0,0002 & 0,70 & 0,0017 & Passou \\
\hline V4 & 1 & 537,75 & 0,38 & 0,0009 & 1,08 & 0,0017 & Passou \\
\hline V5 & 1 & 538,25 & 0,38 & 0,0009 & 1,08 & 0,0017 & Passou \\
\hline V6 & 1 & 364,00 & 0,10 & 0,0002 & 0,73 & 0,0017 & Passou \\
\hline V7 & 1 & 459,50 & 0,40 & 0,0012 & 0,92 & 0,0017 & Passou \\
\hline V8 & 1 & 459,50 & 0,39 & 0,0011 & 0,92 & 0,0017 & Passou \\
\hline V9 & 1 & 538,25 & 0,38 & 0,0009 & 1,08 & 0,0017 & Passou \\
\hline V10 & 1 & 538,25 & 0,38 & 0,0009 & 1,08 & 0,0017 & Passou \\
\hline V11 & 1 & 351,75 & 0,10 & 0,0003 & 0,7 & 0,0017 & Passou \\
\hline \multirow{2}{*}{ V12 } & 1 & 501,75 & 0,08 & 0,0002 & 1,00 & 0,0017 & Passou \\
\cline { 2 - 8 } & 2 & 500,50 & 0,04 & 0,0001 & 1,00 & 0,0017 & Passou \\
\hline \multirow{2}{*}{ V13 } & 1 & 501,00 & 0,04 & 0,0001 & 1,00 & 0,0017 & Passou \\
\cline { 2 - 8 } & 2 & 501,25 & 0,08 & 0,0003 & 1,00 & 0,0017 & Passou \\
\hline V14 & 1 & 378,75 & 0,04 & 0,0001 & 0,76 & 0,0017 & Passou \\
\hline V15 & 1 & 378,75 & 0,04 & 0,0001 & 0,76 & 0,0017 & Passou \\
\hline V16 & 1 & 266,00 & 0,40 & 0,0001 & 0,53 & 0,0017 & Passou \\
\hline \multirow{2}{*}{ V17 } & 1 & 558,75 & 0,11 & 0,0003 & 1,12 & 0,0017 & Passou \\
\cline { 2 - 8 } & 2 & 558,75 & 0,11 & 0,0003 & 1,12 & 0,0017 & Passou \\
\hline \multirow{2}{*}{ V18 } & 1 & 309,42 & 0,01 & 0,0000 & 0,62 & 0,0017 & Passou \\
\cline { 2 - 8 } & 2 & 394,58 & 0,05 & 0,0002 & 0,79 & 0,0017 & Passou \\
\cline { 2 - 8 } V20 & 3 & 333,75 & 0,01 & 0,0001 & 0,67 & 0,0017 & Passou \\
\hline \multirow{2}{*}{ V19 } & 1 & 339,00 & 0,00 & 0,0000 & 0,68 & 0,0017 & Passou \\
\cline { 2 - 8 } V21 & 1 & 309,50 & 0,01 & 0,0000 & 0,62 & 0,0017 & Passou \\
\cline { 2 - 7 } & 3 & 333,50 & 0,05 & 0,0002 & 0,79 & 0,0017 & Passou \\
\hline V22 & 1 & 558,75 & 0,11 & 0,0003 & 1,12 & 0,0017 & Passou \\
\hline V23 & 1 & 379,00 & 0,04 & 0,0001 & 0,76 & 0,0017 & Passou \\
\hline V24 & 1 & 378,75 & 0,04 & 0,0001 & 0,76 & 0,0017 & Passou \\
\hline \multirow{2}{*}{ Foria própria } & $(2017)$ & & & \\
\hline
\end{tabular}

\subsection{Abertura de fissuras}

Foram verificados a evolução dos valores das aberturas de fissuras em cada incremento de carga de cada viga do pavimento tipo, ver Tabela 5, estes devem obedecer ao valor máximo de $w_{\mathrm{k}}(\lim )$ de 0,3 $\mathrm{mm}$, para uma classe de agressividade ambiental definida como II em projeto.

Tabela 5: Abertura de fissuras do pavimento tipo em cada incremento de carga na análise não-linear.

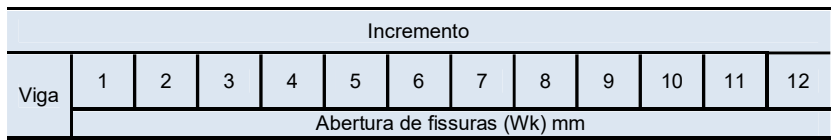

http: / / dx.doi.org/10.25286/repa.v2i3.687 


\begin{tabular}{|c|c|c|c|c|c|c|c|c|c|c|c|c|}
\hline $\mathrm{V} 1$ & 0 & 0 & 10 & 0,00 & 0,00 & 0,00 & 0,00 & 00 & 00 & 10 & 00 & 0,00 \\
\hline$\overline{\mathrm{V} 2}$ & 0,00 &, 00 & 0,00 & 0,00 & 0,00 & 0,00 & 0,00 & 0,00 & 0,00 & 0,00 & 0,00 & 0,00 \\
\hline V3 & 0,00 &, 00 & 0,00 & 0,00 & 0,00 & 0,00 & 0,00 & 0,00 & 0,00 & 0,00 & 0,00 & 0,00 \\
\hline $\mathrm{V} 4$ & 0,00 & 0,00 & 0,00 & 0,00 & 0,00 & 0,00 & 0,00 & \begin{tabular}{|l|}
0,25 \\
\end{tabular} & 0,31 & 0,39 & 0,45 & \begin{tabular}{|l|}
0,49 \\
\end{tabular} \\
\hline V5 & 0,00 & 0,00 & 0,00 & 0,00 & 0,00 & 0,00 & 0,00 & 0,25 & 0,31 & 0,39 & 0,45 & \begin{tabular}{|l|}
0,49 \\
\end{tabular} \\
\hline V6 & 0,00 & 0,00 & 0,00 & 0,00 & 0,00 & 0,00 & 0,00 & 0,00 & 0,00 & 0,00 & 0,00 & 0,00 \\
\hline V7 & 0,00 & 0,00 & 0,00 & 0,00 & 0,00 & 0,00 & 0,15 & 0,19 & 0,23 & 0,25 & 0,28 & \begin{tabular}{|l|}
0,30 \\
\end{tabular} \\
\hline V8 & 0,00 & 0,00 & 0,00 & 0,00 & 0,00 & 0,00 & 15 & 0,19 & 0,23 & \begin{tabular}{|l|l}
0,25 \\
\end{tabular} & 0,28 & 0,30 \\
\hline V9 & \begin{tabular}{|l|l}
0,00 \\
\end{tabular} & 0,00 & \begin{tabular}{|l|}
0,00 \\
\end{tabular} & 0,00 & \begin{tabular}{|l|}
0,00 \\
\end{tabular} & \begin{tabular}{|l|}
0,00 \\
\end{tabular} & \begin{tabular}{|l|l}
0,00 \\
\end{tabular} & \begin{tabular}{|l}
0,25 \\
\end{tabular} & \begin{tabular}{|l|}
0,31 \\
\end{tabular} & \begin{tabular}{|c|}
0,39 \\
\end{tabular} & \begin{tabular}{|l|}
0,45 \\
\end{tabular} & \begin{tabular}{|l|}
0,49 \\
\end{tabular} \\
\hline V10 & 0,00 & 0,00 & 0,00 & 0,00 & 0,00 & 0,00 & 0,00 & \begin{tabular}{|l|}
0,25 \\
\end{tabular} & 0,31 & 0,39 & 0,45 & 0,49 \\
\hline V11 & 0,00 & 0,00 & 0,00 & 0,00 & 0,00 & \begin{tabular}{|l|l}
0,00 \\
\end{tabular} & 0,00 & 0,00 & 0,00 & 0,00 & 0,00 & 0,00 \\
\hline $\mathrm{V} 12$ & \begin{tabular}{|l|l}
0,00 \\
\end{tabular} & 0,00 & \begin{tabular}{|l|}
0,00 \\
\end{tabular} & 0,00 & \begin{tabular}{|l|}
0,00 \\
\end{tabular} & \begin{tabular}{|l|}
0,00 \\
\end{tabular} & \begin{tabular}{|l|l}
0,00 \\
\end{tabular} & \begin{tabular}{|l|}
0,00 \\
\end{tabular} & \begin{tabular}{|l|}
0,00 \\
\end{tabular} & 0,00 & \begin{tabular}{|l|}
0,00 \\
\end{tabular} & \begin{tabular}{|l|}
0,00 \\
\end{tabular} \\
\hline $\begin{array}{l}\mathrm{V} 13 \\
\end{array}$ & 0,00 & 0,00 & 0,00 & 0,00 & 0,00 & \begin{tabular}{|l|}
0,00 \\
\end{tabular} & 0,00 & 0,00 & 0,00 & 0,00 & \begin{tabular}{|l|}
0,00 \\
\end{tabular} & 0,00 \\
\hline V14 & 0,00 & 0,00 & 0,00 & 0,00 & 0,00 & 0,00 & 0,00 & 0,00 & 0,00 & 0,00 & 0,00 & 0,00 \\
\hline V15 & \begin{tabular}{|l|}
0,00 \\
\end{tabular} & 0,00 & \begin{tabular}{|l|}
0,00 \\
\end{tabular} & 0,00 & 0,00 & \begin{tabular}{|l|}
0,00 \\
\end{tabular} & 0,00 & \begin{tabular}{|l|}
0,00 \\
\end{tabular} & \begin{tabular}{|l|}
0,00 \\
\end{tabular} & 0,00 & \begin{tabular}{|l|}
0,00 \\
\end{tabular} & 0,00 \\
\hline V16 & 0,00 & 0,00 & 0,00 & 0,00 & 0,00 & 0,00 & 0,00 & 0,00 & 0,00 & \begin{tabular}{|l}
0,00 \\
\end{tabular} & 0,00 & 0,00 \\
\hline V17 & 0,00 & 0,00 & 0,00 & 0,00 & 0,00 & \begin{tabular}{|l|}
0,00 \\
\end{tabular} & 0,00 & 0,00 & 0,00 & 0,00 & 0,00 & \begin{tabular}{l|l}
0,00 \\
\end{tabular} \\
\hline V18 & 0,00 & 0,00 & 0,00 & 0,00 & 0,00 & 0,00 & \begin{tabular}{|l}
0,00 \\
\end{tabular} & 0,00 & 0,00 & \begin{tabular}{|l}
0,00 \\
\end{tabular} & 0,00 & 0,17 \\
\hline V19 & 0,00 & 0,00 & 0,00 & 0,00 & 0,00 & 0,00 & 0,00 & 0,00 & 0,00 & 0,00 & 0,00 & \begin{tabular}{|l|}
0,00 \\
\end{tabular} \\
\hline V20 & \begin{tabular}{|l|l}
0,00 \\
\end{tabular} & 0,00 & \begin{tabular}{|l|}
0,00 \\
\end{tabular} & 0,00 & \begin{tabular}{|l|}
0,00 \\
\end{tabular} & \begin{tabular}{|l|}
0,00 \\
\end{tabular} & 00 & \begin{tabular}{|l|}
0,00 \\
\end{tabular} & \begin{tabular}{|l|}
0,00 \\
\end{tabular} & 0,00 & \begin{tabular}{|l|}
0,00 \\
\end{tabular} & 0,17 \\
\hline V21 & 0,00 & 0,00 & 0,00 & 0,00 & 0,00 & 0,00 & 0,00 & 0,00 & 0,00 & 0,00 & 0,00 & 0,00 \\
\hline V22 & 0,00 & 0,00 & 0,00 & 0,00 & 0,00 & 0,00 & 0,00 & 0,00 & 0,00 & 0,00 & 0,00 & 0,00 \\
\hline $\mathrm{V} 23$ & \begin{tabular}{|l|}
0,00 \\
\end{tabular} & 0,00 & \begin{tabular}{|l|}
0,00 \\
\end{tabular} & \begin{tabular}{|l|}
0,00 \\
\end{tabular} & 0,00 & \begin{tabular}{|l|}
0,00 \\
\end{tabular} & 0,00 & \begin{tabular}{|l|}
0,00 \\
\end{tabular} & \begin{tabular}{|l|}
0,00 \\
\end{tabular} & 0,00 & \begin{tabular}{|l|}
0,00 \\
\end{tabular} & \begin{tabular}{|l|}
0,00 \\
\end{tabular} \\
\hline $\mathrm{V} 24$ & 0,00 & 0,00 & 0,00 & 0,00 & 0,00 & 0,00 & 0,00 & 0,00 & 0,00 & 0,00 & 0,00 & 0,00 \\
\hline
\end{tabular}
Fonte: Autoria própria (2017).

\subsection{Resultados}

Conforme os valores obtidos, todos os deslocamentos verticais e rotações atenderam a condição limite dos valores-limites analisados no trabalho, na análise não-linear incremental.

Já para a abertura de fissuras o que se pode observar nos resultados obtidos é que grande parte das vigas fissuradas ultrapassam o $w_{\mathrm{k}}(\mathrm{lim})$ de 0,3 $\mathrm{mm}$ para abertura de fissuras, ao longo da análise incremental. O que indica que podem ocorrer patologias quanto à corrosão das armaduras, gerando consequentemente a não aprovação dos usuários.

As aberturas apareceram nas vigas fissuradas a partir do sexto ou sétimo incremento de carga, quando foram solicitadas as sobrecargas e cargas acidentais, conferindo à estrutura um aumento de solicitação e diminuição da rigidez pela fissuração dos elementos estruturais. Na Figura 4 são mostradas as vigas que ultrapassaram limites de fissuração.

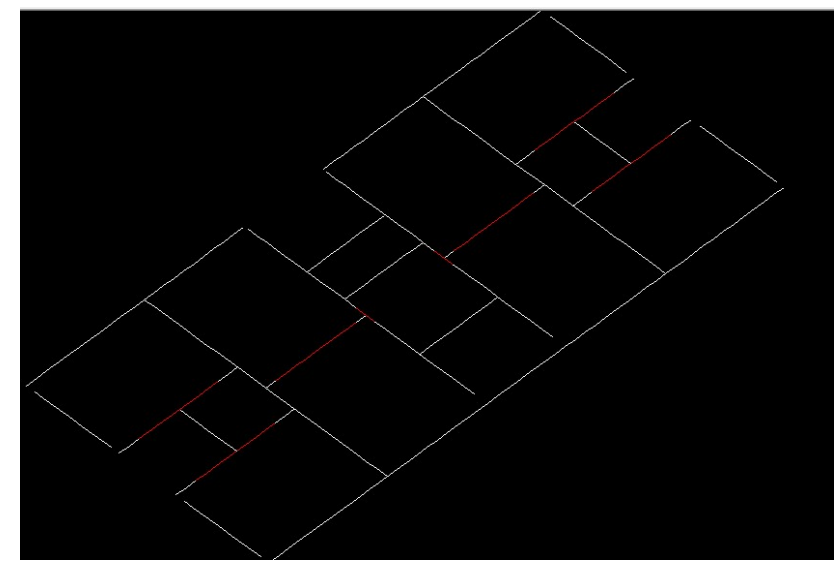

Figura 4: Vigas fissuradas

Fonte: Autoria própria (2017).

\section{Considerações finais}

O aparecimento de fissuras e deformações excessivas são problemas correntes em edificações de concreto armado, estas que por sua vez são comumente encontradas em peças com predominâncias de esforços à flexão. Isso se dá devida à baixa resistência do concreto à tração e a ductilidade deste material.

Ao se projetar uma estrutura, é necessário sempre obedecer aos estados-limites prescritos em norma, pois estes devem garantir parâmetros mínimos de projeto os quais dão uma maior segurança estrutural, como também uma melhor funcionalidade das mesmas. O estado-limite de serviço está correlacionado com a durabilidade da estrutura, como do conforto do usuário, o qual quando respeitado, além aumentar a vida útil da estrutura, garantirá a rentabilidade do investimento.

É de extrema importância se estudar e analisar o projeto antes de sua execução, pois é na fase de projeto que se podem ser observadas falhas com uma maior precisão. Sempre que detectadas falhas ou inconsistências, estas devem ser corrigidas o quanto antes, pois mudanças na etapa de construção e manutenções devido à essas falhas geram gastos muito maiores à longo prazo, o que se deve levar os empresários a investir fortemente na racionalização e otimização de projetos.

No estudo de caso foram encontradas aberturas de fissuras maiores que as permitidas pela NBR 6118, porém nela mesma no item 13.4.2, estes valores-limite para a fissuração devem apenas ser levados em conta a caráter de um bom projeto de estruturas. 
Devido às diversas variáveis envolvendo esta situação, ainda não é possível se chegar ao valor encontrado na vida real, e fenômenos patológicos, também podem ocorrer quando os níveis de fissuração estiverem dentro dos limites estabelecidos. Inclusive carbonatação e o ataque por íons cloretos.

Porém apesar desses valores terem grande variabilidade de grandezas envolvidas, grande parte destas não estava obedecendo aos limites prescritos, o que futuramente poderia acarretar a difusão de agentes agressivos por estas fissuras e consequentemente o aparecimento de patologias decorrentes da degradação do concreto e corrosão das armaduras.

O que torna importante algumas modificações em projeto para atingir os devidos valores-limite para $w_{\mathrm{k}}$, para se evitar futuros transtornos, e despesas de manutenção preditiva, visto que a vontade dos construtores e principalmente dos clientes da construção civil é que as estruturas sejam mais duráveis e que se retire de seus orçamentos gastos com manutenções e reparos.

\section{Referências}

[1] ABNT - ASSOCIAÇÃO BRASILEIRA DE NORMAS TÉCNICAS. NBR 6118: Projeto de estruturas de concreto - Procedimento. Rio de Janeiro, 2014.

[2] AMERICAN CONCRETE INSTITUTE. Comitte 201.2R. Guide to Durable Concrete. ACI Manual of Concrete Pratice, Detroit, 2001, 41p.

[3] ANDRADE, T. W. C. O; COSTA E SILVA, A. J. Considerações sobre durabilidade, patologia e manutenção das estruturas. Acervo Tecomat Tecnologia da Construção e Materiais Ltda, 2009, Recife.

[4] ARAÚJO, J. M. Modelos de previsão da fluência e da retração do concreto. Série Estruturas de Concreto, n. 4, Ed. Dunas, Rio Grande, Abril, 2002, 26.p.

[5] BUCHAIM, R. - A influência da não-linearidade física do concreto armado na rigidez à flexão e na capacidade de rotação plástica. 2001. 260 f. Tese (Doutorado em Engenharia). Departamento de Engenharia de Estruturas e Fundações, Escola 56
Politécnica da Universidade de São Paulo, São Paulo.

[6] CARVALHO, R. C. , FILHO, J. R. F. Cálculo e Detalhamento de Estruturas Usuais de Concreto Armado Segundo a NBR 6118:2014. 2014. 416 p. Editora EduFSCar, São Carlos.

[7] CHAN, H.C.; CHEUNG, Y.K.; HUANG, Y.P. (1994). Nonlinear modelling of reinforced concrete structures. Computers \& Structures, v.53, n.5, p.1099-1107. Hong Kong.

[8] HELENE. P. R. L. Vida útil das estruturas de concreto. In: IV CONGRESSO IBEROAMERICANO DE PATOLOGIA DAS CONSTRUÇÕES. Anais. Porto Alegre, 1997.

[9] KIMURA, A. E. Informática aplicada em estruturas de concreto armado. 2007. 624 p. Editora PINI, São Paulo.

[10] MARINS NETO, J. - Análise Numérica Nãolinear de Estruturas de Concreto Armado Considerando o Fenômeno da Aderência entre o Aço e o Concreto. 2007. 192 p. Tese (Doutorado em Engenharia Civil). Departamento de Estruturas, Universidade Estadual de Campinas, Campinas.

[11] METHA, P.K.; MONTEIRO, P.J.M. Concreto: Microestrutura, propriedades e materiais. Pini, São Paulo, 2014.

[12] THOMAZ, Ercio. Trincas em Edifícios: Causas, Prevenção e Recuperação. São Paulo: PINI, 1989. 194 p.

[13] WANG, T.; HSU, T.T.C. (2001). Nonlinear finite element analysis of concrete structures using new constitutive models. Computers \& Structures, v.79, n.32, p.2781-2791.

http: / /dx.doi.org/10.25286/repa.v2i3.687 


\section{Apêndice I}

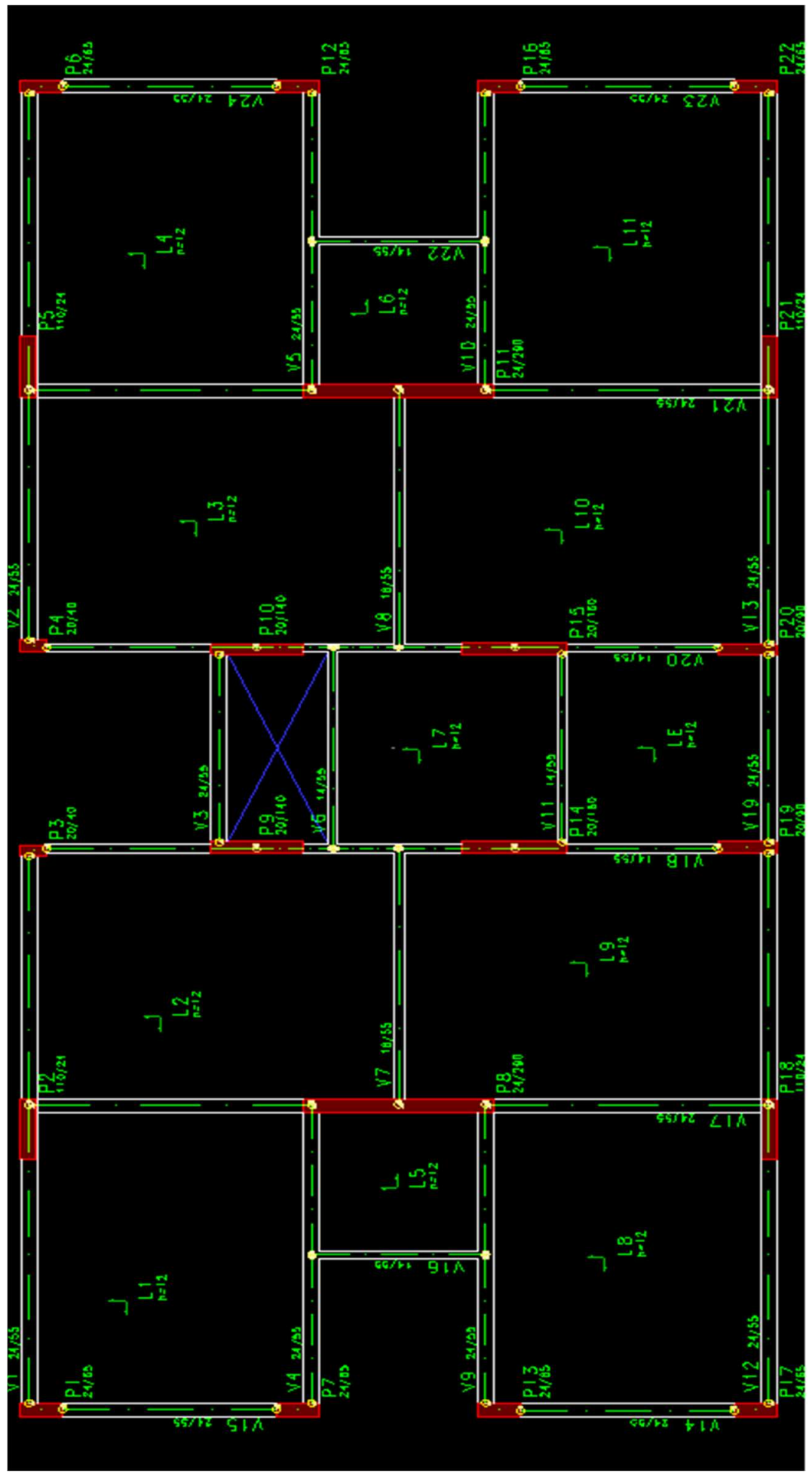

Projeto estrutural do edifício.

Fonte: Autoria própria (2017). 